\title{
INTRADURAL EXTRAMEDULLARY HEMANGIOBLASTOMA
}

\author{
Everton Barbosa-Silva', Gervásio Teles C. Carvalho², Marcelo de Oliveira Frota ${ }^{1}$, \\ Atos Alves de Sousa ${ }^{2}$, Carlos Batista Alves de Souza ${ }^{2}$
}

Hemangioblastoma of the spinal cord was first described by Schultze in 1912, with the first successful resection of this type of tumor performed on the same occasion. In 1928, Cushing and Bailey ${ }^{2}$ proposed the term hemangioblastoma in order to distinguish it from arteriovenous malformations. Hemangioblastomas are highly vascularized rare benign tumors, classified as grade I by the WHO, which are poorly described in the literature. The histogenesis of these tumors is uncertain and they are often cystic $^{3}$ and might be associated with peritumoral edema and/or syringomyelia ${ }^{4}$. Cure is possible by complete surgical excision. The advent of magnetic resonance imaging (MRI) has increased the number of cases of hemangioblastoma described in the literature ${ }^{5}$. The extramedullary location of spinal cord hemangioblastomas is extremely rare ${ }^{6,7}$.

A case of an intradural extramedullary hemangioblastoma in a 66 year-old woman without von Hippel-Lindau disease $(\mathrm{VHL})$ is reported here.

\section{CASE}

A 66 year-old woman presented with a six month history of progressive weakness and paresthesia in the lower limbs accompanied by important walking difficulty and lumbar pain irradiating to the right side of the abdomen. Physical examination showed the presence of paraparesis accompanied by objective signs of pyramidal syndrome, in addition to thermal and painful hypoesthesia, with the sensory level located at T1O. MRI demonstrated an expansive intradural extramedullary lesion at $\mathrm{T} 10-\mathrm{Tl1}$, exerting important compression and left anterolateral deviation of the thoracic spine, with slightly lobular contours, which was homogenously contrast enhancing (Fig 1). An enlarged vascular structure was observed below the lesion (Fig 2).

The patient was submitted to laminectomy from T9 to T12. After opening the dura mater, a cystic reddish tumor was visualized just dorsolateral to the spinal cord. Several tortuous blood vessels were observed around the mass. The tumor was removed en bloc by microdissection on a well-defined cleavage plane.

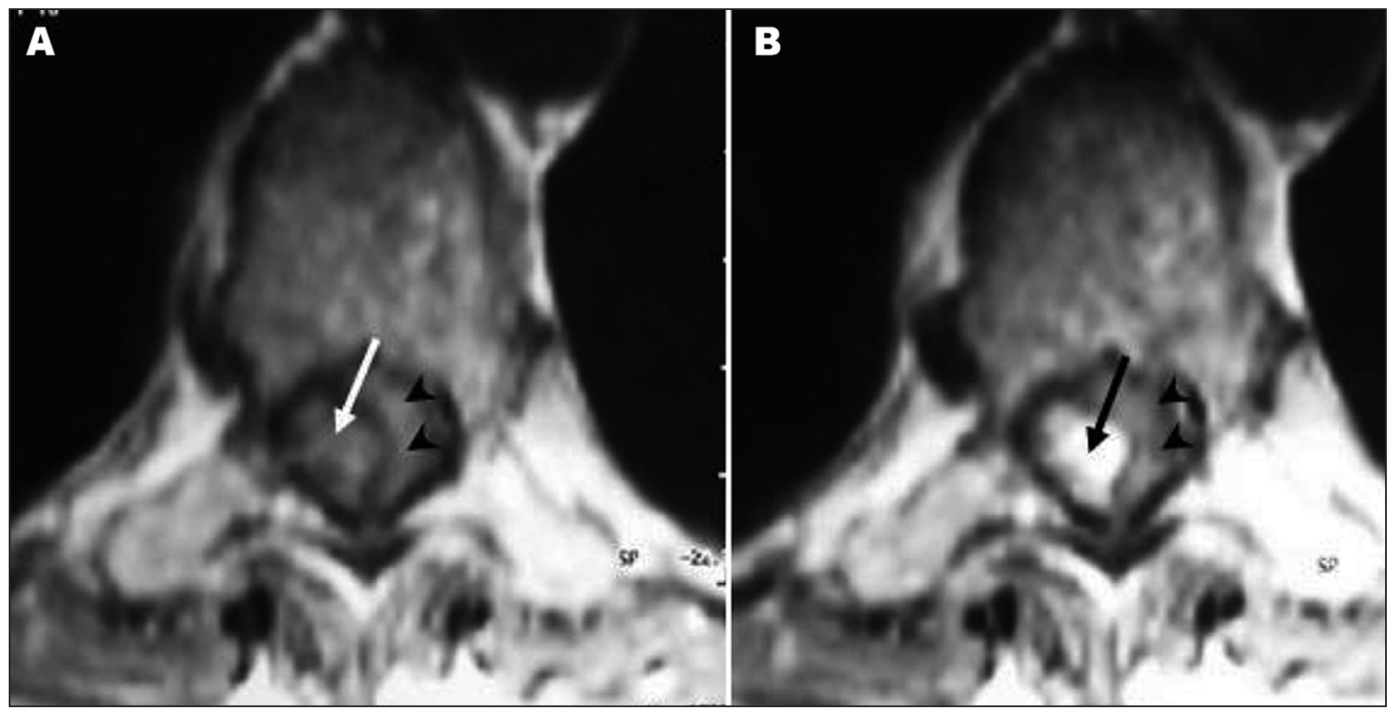

Fig 1. Axial MRI. [A] T7-weighted image reveals an isointense tumor (arrow) clearly separated from the surface of the spinal cord (arrowheads). [B] T7-weighted image with contrast agent shows homogeneous enhancing.

\section{HEMANGIOBLASTOMA INTRADURAL EXTRAMEDULAR}

${ }^{1}$ Resident, Department of Neurosurgery, Santa Casa de Belo Horizonte, Belo Horizonte MG, Brazil; ${ }^{2}$ MD, Department of Neurosurgery, Santa Casa de Misericórdia de Belo Horizonte and Faculdade de Ciências Médicas, Belo Horizonte MG, Brazil. 


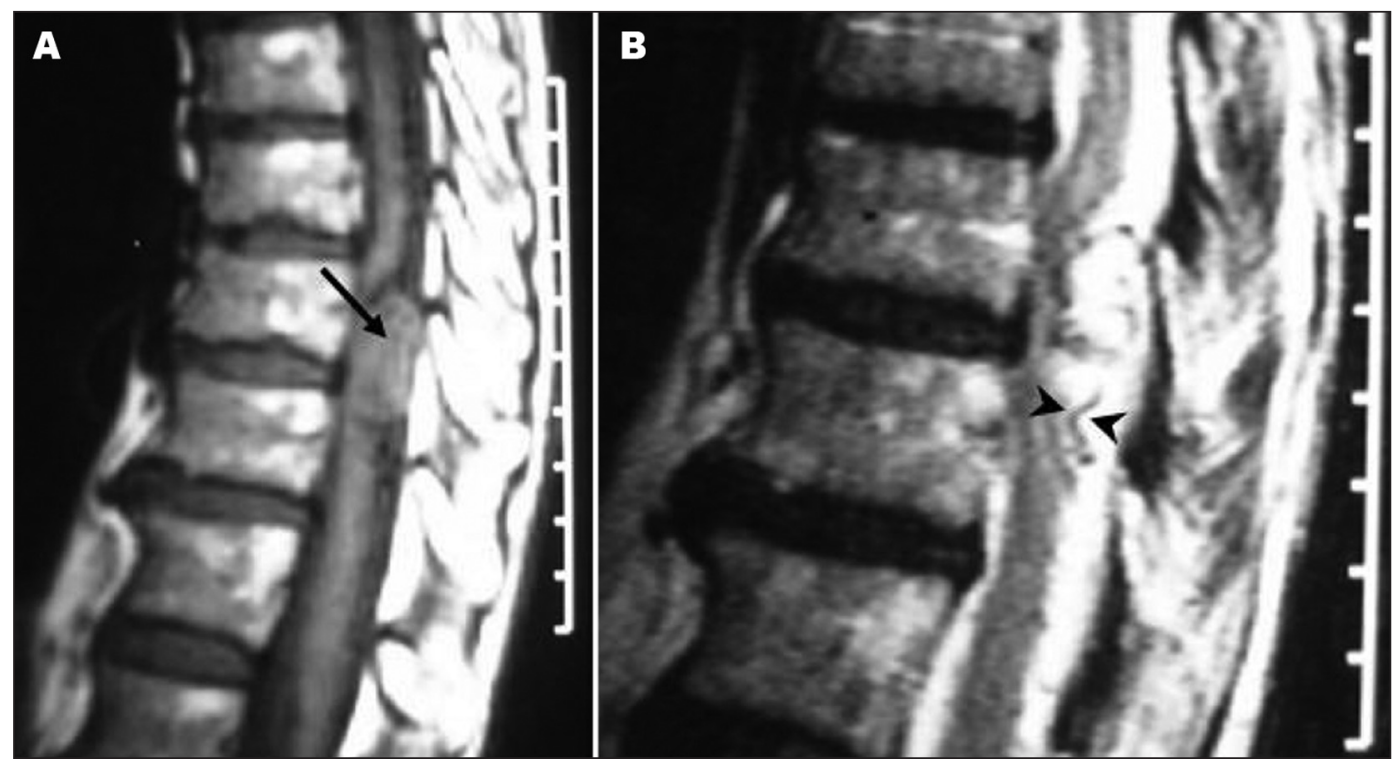

Fig 2. Sagittal MRI. [A] T1-weighted image shows the tumor (arrow) at T10-T11. [B] T2-weighted image reveals an area of low signal, indicating flow void due to abnormal vascular structure (arrowheads).

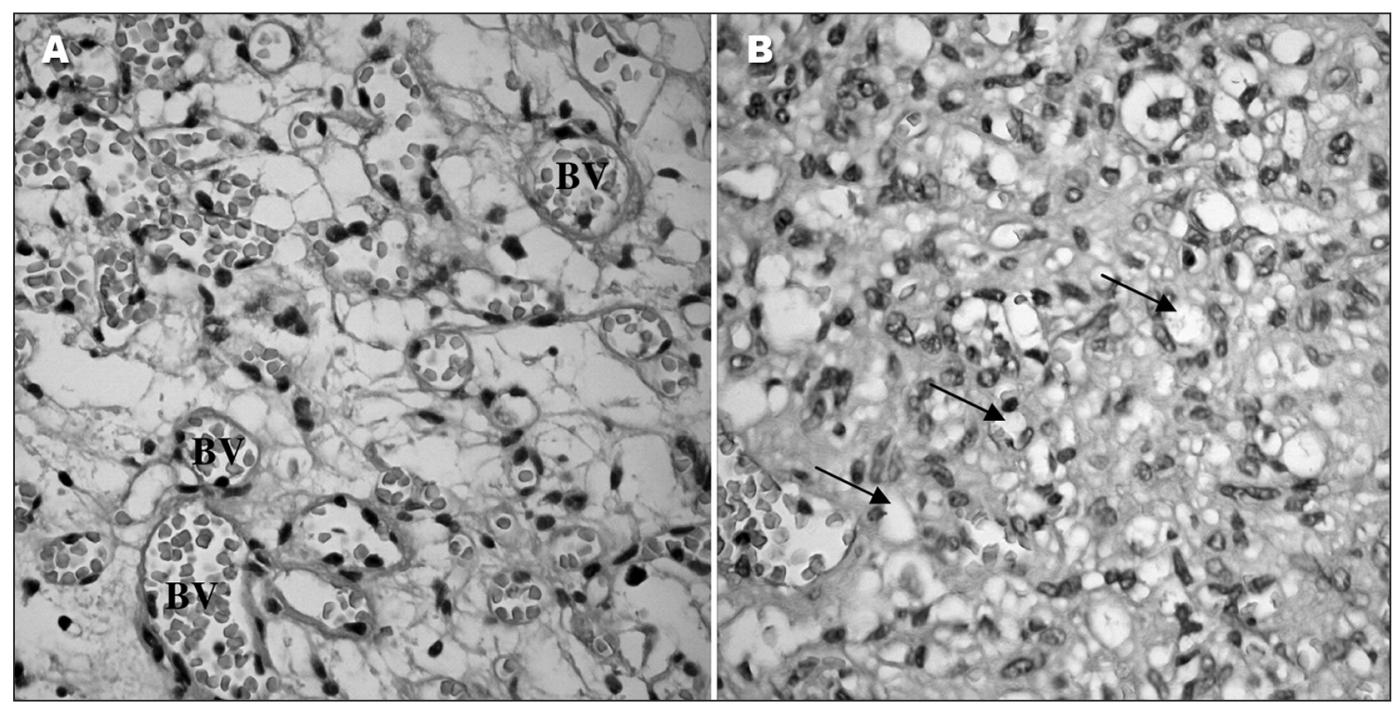

Fig 3. [A] histological section showing the proliferation of blood vessels (BV) lined with endothelium without atypias. [B] vacuolated stromal cells (arrows). Hematoxylin-eosin; X50.

The tumor was adhered to the pia mater and no intramedullary growth was observed.

Histopathological analysis revealed proliferation of blood vessels lined with an endothelium without atypias, intermingled with solid areas consisting of vacuolated stromal cells (Fig 3). The findings were suggestive of hemangioblastoma, a diagnosis later confirmed by immunohistochemical study.

The patient presented important improvement of paraparesis after surgery and was able to walk unassisted after two months, and gave an informed consent to this report.

\section{DISCUSSION}

Sporadic hemangioblastomas are the most frequent form, present in two-thirds of cases. In 20 to $30 \%$ of cases, hemangioblastomas present as multiple tumors located in the cerebellum and retina, generally associated with a dominant autosomal syndrome of incomplete penetrance and expression, known as $\mathrm{VHL}^{7-10}$. The histological characteristics of hemangioblastoma are the same, regardless of whether it is associated with VHL or not ${ }^{4}$.

In general, hemangioblastomas are more frequent in men, with a proportion of $2: 1^{3}$. The mean age at the onset of the sporadic form is 35.5 years, similar to the age of onset of VHL (33 years) ${ }^{4,5}$.

Most spinal hemangioblastomas present intramedullary growth, and are the third general cause of intramed- 
Table. Clinically significant intradural extramedullary hemangioblastomas

\begin{tabular}{cccc}
\hline Case & Author/Year & Age/Sex & Level \\
\hline 1 & Browne et al. ${ }^{8}, 1976$ & $47 / \mathrm{F}$ & T2 \\
2 & Wisoff et al., 1978 & $59 / \mathrm{M}$ & T12 \\
3 & Kitanaka et al. ${ }^{6}, 1993$ & $59 / \mathrm{F}$ & T6 \\
4 & Brisman et al. $.^{16}, 2000$ & $57 / \mathrm{F}$ & Conus medullaris \\
5 & Toyoda et al. ${ }^{17}, 2004$ & $46 / \mathrm{M}$ & C5-C7 \\
6 & Shin et al. ${ }^{18}, 2008$ & $63 / \mathrm{M}$ & T5 \\
7 & Barbosa-Silva et al., 2009* & $66 / \mathrm{F}$ & T10-T11 \\
\hline
\end{tabular}

F; female; M; male; T; thoracic; C: cervical; *present case.

ullary tumors ${ }^{7,11}$. This tumor has been described in all spinal levels, with the cervical and thoracic levels predominating ${ }^{8}$. In 1976, Yasargil et al. ${ }^{12}$ published the first case series of resection of intramedullary hemangioblastomas. These tumors are generally located on the dorsal side of the spinal cord and are visible after opening the dura mater through the pia. Their exophytic growth is well-known 6 . In a review of 85 cases, eight tumors presented simultaneous intra and extramedullary growth ${ }^{8,13}$.

Small and clinically nonsignificant extramedullary hemangioblastomas are well documented in the literature and are generally observed adherent to the cauda equina, filum terminale or anterior and posterior roots of the spinal nerves. It often follows an indolent clinical course and patients do not present specific symptoms, rather radicular pain. In 1975, Hurt ${ }^{14}$ published an extensive review of the literature covering 138 cases, found 38 cases of intradural extramedullary hemangioblastoma, of which 28 were located on nerve roots (including the cauda equina) and 10 cases were extramedullary tumors, as in the current report, but these occurred in patients that presented signs of VHL or were asymptomatic and showed incidental findings at autopsy. Browne et al. ${ }^{8}$ and Yasargil et al..$^{2}$ reported an incidence of $21.3 \%$ and $25.3 \%$, respectively, for this type of presentation of this tumor. In 2003, Costa Jr et al..$^{15}$ described an exceptional case of cauda equina hemangioblastoma diagnosed by MRI, in a 48-years-old woman without VHL, who presented with paresthesia and discreet weakness in the left leg.

Purely extramedullary and clinically significant hemangioblastomas demonstrated by CT or MRI are extremely rare in patients without $\mathrm{VHL}$ disease $\mathrm{e}^{6,7}$.

In a review of the literature analyzing studies published in the Medline database after 1966, we found six well-documented cases of clinically significant extramedullary hemangioblastoma, as in the present case (Table).

Despite the low incidence of intradural and purely extramedullary hemangioblastomas, special attention should be paid to the differential diagnosis of this tumor with other extramedullary neoplasms, such as men- ingiomas and nerve sheath tumors. In this location the appearance is similar. Moreover, both frequently occur in the thoracic spine of middle-aged women. The possibility of hemangioblastoma should not be ruled out by the neurosurgeon when treating an intradural extramedullary tu$\mathrm{mor}^{6}$. The key to preoperative diagnosis is the recognition of marked enhancement and associated enlarged vessels on the MRI ${ }^{19}$. This feature also makes an important distinction between hemangioblastoma and spinal cord vascular malformation. Brisman et al. ${ }^{16}$ emphasized the need for selective spinal angiography in the preoperative diagnosis and recommended surgical treatment as a first line of therapy. For Shin et al. ${ }^{18}$, angiography shows limited usefulness in the operative fields. In the present case, MRI was sufficient for an effective and safe surgery.

In conclusion, the possible presence of a hemangioblastoma should always be considered in cases of extramedullary lesions. Complete surgical excision is the procedure of choice and in this case the patient presented an excellent return to normal neurological status at two months follow-up.

\section{REFERENCES}

1. Schultze F. Weiterer Beitrag zur Diagnose und operativen Behandlung von Geschwülsten der Rückenmarkshäute und des Rückenmarks. Deutsch Med Wochenschr 1912;38: 1676-1679.

2. Cushing H, Bailey P. Tumors arising from the blood vessels of the brain: angiomatous malformations and hemangioblastomas. Springfield: Charles C Thomas, 1928:105-109.

3. Adams JP, Duchen L. Greenfield's Neuropathology. $5^{\text {th }}$ Ed. London: Edward Arnold, 1993.

4. Lonser RR, Weil RJ, Wanebo JE, DeVroom HL, Oldfield EH. Surgical management of spinal cord hemangioblastomas in patients with von Hippel- Lindau disease. J Neurosurg 2003; 98:106-116.

5. Roonprapunt C, Silvera VM, Setton A, Freed D, Epstein FJ, Jallo GI. Surgical management of isolated hemangioblastomas of the spinal cord. Neurosurgery 2001;49:321-328.

6. Kitanaka C, Kuwahara M, Teraoka A. Intradural, purely ex- 
tramedullary hemangioblastoma of the spinal cord: case report. Neurol Med Chir 1993;33:377-380.

7. Wisoff HS, Suzuki Y, Llena JF, Fine DI. Extramedullary hemangioblastoma of the spinal cord: case report. J Neurosurg 1978; 48:461-464.

8. Browne TR, Adams RD, Robertson GH. Hemangioblastoma of the spinal cord. Review and report of five cases. Arch Neurol 1976;33:435-441.

9. Murota T, Symon L. Surgical management of hemangioblastoma of the spinal cord: a report of 18 cases. Neurosurgery 1989; 25:7699-7708.

10. Neumann H, Eggert H, Weigel K, Friedburg H, Wiestler O, Schollmeyer P. Hemangioblastomas of the central nervous system. J Neurosurg 1989;70:24-30.

11. Baleriaux DL. Spinal cord tumors. Eur Radiol 1999;9:12521258.

12. Yasargil MG, Antic J, Laciga R, de Preux J, Fideler RW, Boone SC. The microsurgical removal of intramedullary spinal hemangioblastomas: report of twelve cases and a review of the literature. Surg Neurol 1976;3:141-148.
13. Corr P, Dicker T, Wrigth M. Exophytic intramedullary hemangioblastomapresenting as an extramedullary mass on myelography. AJNR 1995;16:883-884.

14. Hurt M. Les hemangioblastomas intrarachidiens. Neurochirurgie 1975;21:1-136.

15. Costa LB Jr, Andrade A, Braga BP, Ribeiro CA. Cauda equina hemangioblastoma: case report. Arq Neuropsiquiatr 2003;61: 456-458.

16. Brisman JL, Borges LF, Ogilvy CS. Extramedullary hemangioblastoma of the conus medullaris. Acta Neurochir 2000;142: 1059-1062.

17. Toyoda H, Seki M, Nakamura H, Inoue $Y$, Yamano $Y$, Takaoka K. Intradural extramedullary hemangioblastoma differentiated by MR images in the cervical spine: a case report and review of the literature. J Spinal Disord Tech 2004;17: 343-347.

18. Shin DA, Kim SH, Kim NH, Shin HC. Surgical management of spinal cord haemangioblastoma. Acta Neurochir 2008;150:215-220.

19. Baker KB, Moran CJ, Wippold FJ, et al. MR imaging of spinal hemangioblastoma. Am J Roentgenol 2000;174:377-382. 